\title{
Private V. Public Health Care System in Canada: A Revisit to The Chaoulli V. Quebec Court Case
}

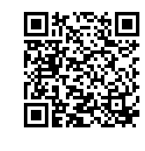

\author{
Jesse Tremblay and Bosu Seo* \\ Department of Economics, University of the Fraser Valley, Canada
}

Submission: April 03, 2019; Published: May 03, 2019

*Corresponding author: Bosu Seo, Department of Economics, University of the Fraser Valley, Canada

\begin{abstract}
This paper focuses on the debate between private v. public health care in Canada with a specific look at the Chaoulli v. Quebec court case from [1]. The case primarily revolved around increasing wait list times and the inability for those wishing to use private insurance to gain timely access to surgeries. The case was critical of a ban on private health insurance and is in line with a Canadian public that is increasingly skeptical as to whether Canada's current mix of health care is the right one. Finally, a framework is set up in order to evaluate the full impact that an injection on private insurance would have on wait lists times.
\end{abstract}

Keywords: Private Health Care; Public Health Care; Canadian Health Care System; Wait Time; Chaoulli V. Quebec Case

\section{Introduction}

Chaoulli v. Quebec is a seminal court case in the Canadian debate for equitable health care. As such, the case is a natural pivot point for the future of health care in the country. While many have rightly pointed out that Canada's healthcare system is a source of national identity Coletta [2], Forget [3] \& Crites [4] there is mounting negative coverage in both the press and academia on the long-term feasibility of the current healthcare mix. As wait list times grow longer in Canada, it is starting to become unclear, for many, why Canadians continue to link our national identity with healthcare. As mentioned, one of the issues that routinely comes up when talking about Canadian health care are wait times. A study by Wayne Taylor [5] analyzing a report that compared Canada's healthcare system with systems in Europe noted that "[w] ait times were Canada's weakest spot" and that "amalgam of healthcare is out of the equilibrium" (2012). Taylor's critical assessment of the wait times in Canada need not be the only determining factor in assessing the equilibrium of a health care system; however, as this paper will note, wait times are a critical factor in the perception of the health care systems ability to deliver services. In fact, one does not have to look far to see that long wait times are almost becoming as synonymous with Canadian identity as health care itself. Mainstream media sources are frequently reporting on extreme cases of long wait times; one Ontario doctor was told that her patient could expect "a 4.5-year wait to see a neurologist" Puzic [6]. While, as stated, this may be an extreme case, and the wait time benchmarks set in Canada are far lower than that, wait times greater than six months are still not rare.

To complicate matters, as long cases of wait times become all too common in a system that is struggling to find ways to lower them, Canada's population continues to age as the baby-boomer generation heads towards retirement. Thus, the strain on the health care system is unlikely to ease any time soon and the healthcare system has an important economic question that must be addressed: how will the country pay for healthcare services as the population ages while reducing wait times?

\section{Public Perception and Spending}

With the conversation around wait times looming, Canadians are warming up to the idea of health care reform: a 2012 poll of Canadians found that "three-quarters of them support being able to buy private health insurance" Stechyson [7]. Those results do not seem consistent with a country that has built its national identity over the last 35 years on our healthcare system. They signal increasing awareness from the general public; a growing consciousness that will soon force provincial governments into action, and, if they act too leisurely, reaction. However, even as the idea of reform gains more public favor, there are still those who are hostile to the idea, or at least, antagonistic towards a reform that is based on an increase in the private sector. For example, an article from The Economist noted that "[m]uch of the opposition to private delivery comes from powerful public-sector unions" [8]. While much of that job action was directed at support staff Armstrong [9] rather than the actual delivery of healthcare, it is hard to imagine that such job action will be met with strong support from the public if the choice is between standing by unions or receiving a better mix of healthcare services.

Nor is spending the issue. Since 1984, the year the Canada Health Act was passed into law, ushering in the modern era Canadian health care, healthcare costs in Canada have risen from 
$\$ 39,842,400,000$ to $\$ 214,907,200,000$ in 2014 (or a difference of $8 \%$ to $11 \%$ of GDP), even as the public sector share changing from $76.1 \%$ to $70.5 \%$ over this time National Health Expenditure Trends [10]. Most hospital and physician costs continue to be financed by the public sector; whereas, the private sector deals primarily with the costs of prescription drugs, dental work, elective surgeries, and other similar medical costs. Thus, the drop in the proportion of the spending on healthcare is mostly on secondary care services rather than primary care.

For its part, the Canada Health Act attempts to guide the way that provincial and territorial bodies provide services to Canadians with the support of the federal government, which provides many logistical services such as regulation, research, and transfer payments, and further administers healthcare to Indigenous peoples and institutionalized citizens Canada Health Act [11]. Provinces also have their own health acts and regulations that manifest in different ways, and Quebec, where the Chaoulli case took place, is no exception. As will be highlighted in the next section of this paper, it was the Quebec Health Act, not the Canada Health Act, that became the focus of the court decision in the Chaoulli case. This distinction is duly important as it may insulate the Canada Health Act, to some extent, from the repercussions stemming from said decision.

\section{The Chaoulli Case}

\section{The Purpose of The Pre-Chaoulli Quebec Health Care System}

Beginning in 2004 and stretching into 2005, the case of Chaoulli v. Quebec sought to contest "the validity of the prohibition on private health insurance" Chaoulli v. Quebec [1] The appellant's main argument relied on the personal cost of waiting times to those who are denied access to private insurance that could otherwise have made use of such insurance to reduce their waiting times. Deeply connected to the issue of personal costs was the notion that the denial of private health insurance was a humanitarian cost that served to infringe the rights of the individual.

The Quebec government had a different perspective and justified "the prohibition on private insurance ... to preserve the integrity of the public health care system" Chaoulli v. Quebec [1]. Essentially, the axiom on which their argument rested was that prohibiting private insurance would prevent private insurers from crowding out the public insurance system. The court, however, remained unconvinced that the prohibition of private medical insurance will lead to an optimal social solution; however, the court also did not outright deny that some limitation on access to private insurance could lead to an optimal solution. In their judgement, they questioned whether an "absolute prohibition" is necessary, which leaves the door open for some form of prohibition. The onus being left on the government to find and prove an optimal level. Furthermore, it is hard to intuit what the reasoning behind a complete ban on private health insurance could hope to achieve in a system that prevents patients from opting out of said system. Afterall, private physicians and insurers would only be reducing the costs for those already in the system that no longer have to bear the costs of health insurance for those that can afford it without the need for a social safety net.

\section{Quality of Care Concerns}

If the purpose of preventing private insurance is a case of protecting the public from for-profit agencies that only care about profit, then the question of quality must come up. A for-profit physician or insurer is only dangerous if they decide to trade quality for profit. If an insurer is faced with a competitive market, then quality is an excellent way for said insurer to differentiate themselves from the competition. However, a government engaging in anti-competitive behavior has no incentive to differentiate from competition unless said competition is other political parties. Since it becomes unclear, in the short run, which government is responsible for which quality of care, there is unlikely to be a strong incentive for long-term political solutions that do not see immediate results.

Thus, it is important to question the quality of care that the government, as an entity not as individual political parties, has provided in the realm of healthcare. As the court notes, "the quality objective is not formally stated, but it seems clear that a health care service that does not attain an acceptable level of quality of care cannot be regarded as a genuine health care service" (Chaoulli v. Quebec, 2005). This is an extremely pejorative view of a healthcare system that fails to live up to the standards of acceptable quality of care; however, quality of care can be difficult to measure. A clear metric, then, must be defined in any conversation on quality of care.

\section{Wait List Times as A Measure of Quality}

The court, as it was relevant to this case, used wait list times as one of the objective ways of measuring quality, finding: "delays in the public health care system are widespread, and ... patients die as a result of waiting lists for public healthcare" Chaoulli v. Quebec [1] and as such, the government failed "to deliver health care in a reasonable manner, thereby increasing the risk of complications and death" Chaoulli v. Quebec [1]. Using wait list times as a metric further weakens any argument against the quality of care that private insurers and physicians would provide as it directly accused the government of Quebec as being complicit, or at least negligent, in the deaths of people in the province who could have received healthcare but did not.

However, the case also makes a point that "the Quebec health plan shares the policy objectives of the Canada Health Act, and the means adopted by Quebec to implement these objectives are not arbitrary" Chaoulli v. Quebec [1]. Meaning that, among other things, the province's healthcare plan takes great consideration for trying to find a means of implementing their health care plan that is in the social interest. Nor does the court believe they should be the arbiters of what the best healthcare policy is when they state that "shifting the design of the health system to the courts is not a wise outcome" Chaoulli v. Quebec [1]. As the courts showed 
restraint in their decision, this lead the doors open as to what would happen next. And what happens next is entirely dependent upon the government in charge and not the results of the Chaoulli case; however, the decision of the courts does, at the least, imply that what the government was doing at the time was not enough.

\section{The Chaoulli Implications}

The Chaoulli case itself is of interest to the private vs public healthcare debate illustrated above because many believed it could open Pandora's box, allowing not only an injection of private healthcare into the Canadian system but far-reaching negative consequences. Patrick Monahan noted that when the decision was brought forward "concerns were raised that due to our international trade commitments, specifically under NAFTA, Chaoulli may irrevocably destroy public healthcare" [12]. However, other opinions on the decision have been more tempered ranging from those that point out the decision only affects the Quebec Charter Flood \& Xavier [13] to those that point out the government's response to the ruling was narrow Labrie [14].

As it turns out, the former opinion was a stretch. While similar cases have been raised in other provinces, not all have been successful. In 2015, for example, an Alberta man lost a case against what Jen Gerson of the National Post calls "Alberta government's monopoly system" [15]. The public healthcare system has not been destroyed by that ruling, and it never was in danger of being destroyed. The Quebec government even maintained the right to veto the Chaoulli decision but chose not to Palley, Pomer, \& Forest [16]. Whether that decision was, at the time, from political grandstanding or a genuine belief on the government's part that an injection of private insurance could help balance the healthcare sy stem of Quebec is up for debate. But the government certainly appeared to take the decision seriously at first.

Shortly after the Chaoulli decision, the Quebec government tabled Bill 33 - a bill that provides physicians that are "member[s] of the Collège des Médecins du Québec" and maintains that the physicians must own "more than $50 \%$ of the voting rights" Quebec official publisher [17] in a private practice. These centers may allow for a small range of surgeries and had the potential to completely change the public-private mix of healthcare within the province, and perhaps serve as a model that could change the mix of healthcare within the country. Later, Claude Castonguay, as commissioned by the Quebec government, would recommend "that the solution to Quebec's health care difficulties lies in allowing certain services presently covered by the public sector . . . to be provided privately by commercial enterprises and reimbursed by private commercial insurance" As cited by Palley et al.[16] Quebec went so far as to provide a strong baseline for private care and hosts some well-known and reputable private hospitals. Thus, the government's decision not to veto may have led to an increase in private spending in the province. Since the Chaoulli decision, private spending on physicians has increased from $\$ 66$ million to $\$ 218$ million, an increase of $230 \%$, and the private share of spending on health has only increased from $28.8 \%$ to $30.5 \%$ over the same period (CIHI, 2018). Nevertheless, the spending on private physicians still pales in comparison to the spending on publicly funded physicians as most physicians are not willing to move into the private sector.

The reason for this is likely due to a government that, although they showed signs of reform, has left laws in place that prevent physicians from both staying in the public system while simultaneously working for the private system. Instead, Quebec physicians must opt out of the provinces Medicare program and an increasing number are choosing to do so with over 400 as of this year Derfel [18]. As the government maintains systems of disincentives that prevent physicians from working in the public sector and private sector, the volume of hip replacements, knee replacements, and cataract surgeries continues to increase at a high rate. These are the three types of surgeries that Bill 33 allowed private physicians to cover. Hip replacements have seen an $81.6 \%$ increase, knee replacements have seen a $99.6 \%$ increase, and cataract surgeries have seen a $37 \%$ increase from 2008 to 2017 respectively (CIHI, 2018) as Quebec's population continues to age.

Forcing physicians to opt out of the publicly funded system in order to provide a service that will benefit the system seems counter-intuitive at best. As wait times continue to increase in Quebec, and across the country, there are mounting questions as to how the systems are run. Taylor points out that "[i]f wait times are a reasonable proxy for measuring equilibrium within a publically funded system ... then the colloquial mantra of the medical profession, 'do no harm,' is certainly being violated in Canada" (2012).

Taylor's heavy-handed judgement of the system may or may not be fair, and many have been quick to point out that wait times are not merely a Canadian phenomenon in healthcare. Flood and Xavier note "the presence or absence of a Canadian 'monopoly' on health insurance for medically necessary care does not correlate with the existence of wait lists or long waiting time" (2008). While that might be true, that does not imply that preventing private insurance from the healthcare system will reduce waiting times either. A Commonwealth fund study found that wait times to meet a specialist were lower in the United States [19], which has a two-tier system, versus Canada. However, long wait times are not necessarily the norm amongst countries with single payer systems.

Limiting patient options through disincentives is not dissimilar to why the Chaoulli case made it to courts in the first place; however, the government has, perhaps cleverly, done so in such a way that they can claim they have opened up access to the private insurance sector but there is little interest in opening up access further. While malicious intent may not be present in the government's treatment of reforms, aside from the short period after they passed Bill 33, they appear to have fallen short in their attempts to improve the healthcare system in Quebec. Money spent by private consumers of healthcare is money that the government does not have to spend at a future date, and it appears that private consumption has increased in spite of government reluctance. 
In a literature review of the efficiency of for-profit versus notfor-profit hospitals, Currie, Donaldson \& Lu [20] found that most studies did not find a significant difference in the efficiency between the two types (2003). Although this is an interesting finding, it does not go to any lengths towards determining whether there should be more private hospitals in Canada. In fact, their finding might even support the idea of more private hospitals. If there is no efficiency difference, and the injunction of more private hospitals into the population means, ceteris paribus, that there will be more hospitals of the same efficiency, then private spending on hospitals might be warranted as it would increase social utility.

\section{Did the Chaoulli Case Help Quebec?}

The Canadian Institute for Health Information releases information every year on waiting list times; however, the methodology they use is based on percentages meeting a benchmark time for receiving health care. Note: All data used in this section comes from CIHI [21,22]. For example, in 2008, 90\% of hip replacements were meeting the benchmark of receiving surgery within 180 days, but in 2017, this number had dropped to $83 \%$. The days it took to get surgery went up across the board with $50 \%$ of those receiving surgery going up from 69 to 93 days during this period. These numbers suggest that the healthcare system is getting unambiguously worse; however, this is not altogether clear. It is important not to overlook the volume of surgeries performed over this period. These surgeries went up from 1,857 in 2008 to 3,373 in 2017 or an increase of $81.6 \%$. When one accounts for the increase in volume, it is no longer clear whether the healthcare system is inefficient just due to an increase in wait times.

Much of the onus on establishing whether the Chaoulli case had a positive effect on wait times stems from whether private Table 1: Surgeries per million $\$$ spent on physicians by type. spending on the types of surgeries that private physicians were able to perform following the case has increased, and how efficiently that spending has been divulged. The government's numbers on their spending on these surgeries are difficult to access, and private spending on these surgeries are not in the public record at all. Thus, this paper merely sets up a framework for future study on the issue. This issue is approached the manner in a couple of different ways. The first way is in the form of a regression analysis on the volume of hip surgeries, knee replacements, and cataract surgeries in Quebec from the years 2008 to 2017. Since volumes alone are bound to go up, this framework would instead look at the proportion of total health dollars spent on physicians in both the public and private sector. This is, admittedly, not necessarily useful as dispersal of money in the health care sector covers far more than just these three surgeries. Thus, the second approach just provides the framework in which an injection of private spending into the health care sector could be evaluated with perfect information.

\section{Approach One}

The first approach uses simple linear regressions on the three different types of surgeries. The data is broken down into (Table 1) as follows: As can be seen from the descriptive data, there are far less cataract surgeries performed in 2017 per million \$ spent on physicians than in 2008. The regression analyses analyze this data in terms of spending as a predictor for volume of surgeries performed. The results of the regression analyses were, at a $99 \%$ confidence interval, overall spending was a very good predictor of the volume of surgeries that were performed in the cases of knee replacements and hip surgeries, with R-squared values of .893 and .916 respectively, but not as good of a predictor of cataract surgeries, with an R-squared value of .629.

\begin{tabular}{|c|c|c|c|c|c|c|c|c|c|c|}
\hline Surgery/Year & $\mathbf{2 0 0 8}$ & $\mathbf{2 0 0 9}$ & $\mathbf{2 0 1 0}$ & $\mathbf{2 0 1 1}$ & $\mathbf{2 0 1 2}$ & $\mathbf{2 0 1 3}$ & $\mathbf{2 0 1 4}$ & $\mathbf{2 0 1 5}$ & $\mathbf{2 0 1 6}$ & $\mathbf{2 0 1 7}$ \\
\hline Cataract & 7.87 & 7.88 & 7.63 & 7.53 & 7.85 & 7.62 & 6.84 & 6.11 & 5.75 & 5.59 \\
\hline Knee & 0.62 & 0.63 & 0.69 & 0.69 & 0.80 & 0.74 & 0.71 & 0.69 & 0.67 & 0.64 \\
\hline Hip & 0.44 & 0.46 & 0.39 & 0.44 & 0.49 & 0.47 & 0.45 & 0.44 & 0.42 & 0.41 \\
\hline
\end{tabular}

However, as previously stated, this information is not necessarily useful without the true cost of physicians spent on each type of surgery. Furthermore, this does not answer the question of the influence of private spending. While private spending on physicians has increased by $121 \%$ over this period in time, they represent just a fraction (around 2.5\%) of total spending on physicians. This does not mean they perform the same fraction of surgeries. Total spending on physicians represents total spending on all types of physicians, and it is likely that very little of the public spending is on these types of surgeries, while it is possible that the majority of spending in the private market for physicians is on these types of surgeries due to the limited range of surgeries that can be performed by private physicians. This leads to the next part of this paper: what it would be like to have perfect information.

\section{Approach Two}

With perfect information about spending, it would be useful to make a look at the proportion of the average cost of surgeries borne by each sector. The equation below describes average cost:

$$
\frac{\beta^{*} \text { private spending }+\alpha^{*} \text { public spending }}{\text { volume performed }}=\text { average cost }
$$

Where is the proportion of spending by the private sector physicians on a type of surgery; private spending is the total private spending on physicians in the province; is the proportion of public sector spending on a type of surgery; public spending is the total public spending on physicians in the province; and volume performed is the number of surgeries performed within the benchmark.

The proportion of average costs turns out to be: 


$$
\frac{\left(\frac{\beta^{*} \text { private spending }}{\text { volume performed }}\right)}{\left(\frac{\alpha^{*} \text { public spending }}{\text { volume performed }}\right)}=\text { proportion of average cost }
$$

With this proportion of the average cost, a regression could be used, to find out whether as the private sector bears more of a burden of a certain type of surgery, health care outcomes improve. In this equation, volumes would cancel out; however, if volumes performed by each sector were known, then average cost per surgery in both sectors would be known and this equation would serve to provide a framework for efficiency in the private and public sectors. A value of 1 would mean that both sectors are equally efficient, a value of greater than 1 would mean that the private sector is more efficient and vice-versa, less than 1 would mean that the public sector is more efficient assuming that each surgery performed provides the same utility. Efficiency is important; although, a more efficient private sector may be on such a small scale that it does not actually benefit health outcomes.

This would go a long way towards understanding what sector should be invested in for more efficient outcomes. Furthermore, average costs could be compared to one another independently in order to see whether the reduction in average costs from one sector is correlated to the reduction of average costs in the other sector (or the effect that competition might be having on both sectors). As this paper focuses on wait times, a reduction in health care costs does not necessarily lead to shorter wait lists, so efficiency alone might not be enough. But as we are operating with perfect information in this scenario, if individual times spent on wait lists were also available, we would be able to compare whether the competitive framework established in the previous paragraph also leads to shorter times spent on wait lists. I would construct an equation as in the following:

\section{volume performed by private

volume performed by public

And compare it to the efficiency equation to see if one sector being more efficient leads to an increase in the volume of surgeries performed by that sector. If it is the case that a more efficient private sector leads to a greater proportion of surgeries being performed by that sector (as a proportion of total surgeries), than the private sector should be allowed to flourish; however, if a more efficient private sector leads to less surgeries performed by the private sector (as a proportion of total surgeries), then it will be clear that private spending is not going to alleviate the stress on the healthcare system.

\section{Summary and Conclusion}

Healthcare spending in Canada has re-emerged into national attention. Canadians, for their part, seem to be mobilizing against the idea that a system that systematically prevents competition is in their best interests. While most agree that a robust public sector in healthcare is a social good, increased criticism of a system that prevents private insurance for those willing to pay is well-founded. The Chaoulli case may have been the most prominent example of a citizen and his physician, exasperated by the healthcare process, bringing the government to court over healthcare wait lists. While the repercussions of the Chaoulli decision are hard to measure - how much, for example, of the latest court cases are due to Chaoulli - there have been mixed beliefs about what the case really means for Canada. Some, for example, believe that the government's response was inadequate in addressing the issue at hand. Others look towards other countries to see if our model is indeed what has been sold to us.

In any case, healthcare costs are rising in Canada at a rapid rate. The population is aging and wait lists times are increasing. Unfortunately, analyzing whether the increase in private healthcare spending has had any impact in the Chaoulli case is not measured in this paper, due to data availability issues, this paper attempted to lay out of a framework to analyze that spending if the data, or should the data, becomes available. Until all data is made publicly available, however, the question of what mix of healthcare in Canada is correct remains open.

\section{References}

1. Chaoulli v Quebec (Attorney General) (2005) 1 S.C.R. 791, 2005 SCC 35.

2. Coletta A (2018) Canada's health-care system is a point of national pride. But a study shows it's at risk of becoming outdated. The Washington Post.

3. Forget E (2002) National Identity and the Challenge of Health Reform in Canada. Review of Social Economy.

4. Crites V (2002) The Canadian identity and the right to health care: From waitlists to social citizenship? The University of British Columbia.

5. Taylor W (2012) Finding Canada's healthcare equilibrium. Healthcare Management Forum.

6. Puzic S (2017) 'It's insane': Ont. patient told she'd have to wait 4.5 years to see neurologist. CTV News.

7. Stechyson N (2012) Canadians want choice in how they access health care: poll. Postmedia news.

8. The Economist (2004) Fistfuls of health dollars; Canada's election campaign. The Economist, 371(8378), 33(US).

9. Armstrong J (2004) BC Makes Move in Health Workers Strike. The Globe and Mail.

10. National Health Expenditure Trends 1975 to 2014 (2014). Canadian Institute for Health Information. a

11. Canada Health Act (2017) Government of Canada.

12. Monahan P (2006) Chaoulli v Quebec and the Future of Canadian Healthcare: Patient Accountability as the "Sixth Principle" of the Canada Health Act. C.D. Howe Institute.

13. Flood C, Xavier S (2008) Health Care Rights in Canada: The Chaoulli Legacy. International Journal of Law and Medicine.

14. Labrie Y (2015) The Chaoulli decision and health care reform: A missed opportunity? Montreal Economic Institute.

15. Gerson J (2015) John Carpay: Court ruling has denied a man his charter right to timely healthcare. National Post.

16. Palley H, Pomey M, Forest P (2011) Examining private and public provision in Canada's provincial health care systems: Comparing Ontario and Quebec. International Political Science Review / Revue Internationale De Science Politique 32(1): 79-94. 
17. Quebec official publisher (2006) An Act to amend the Act respecting health services and social services and other legislative provisions.

18. Derfel A (2018) More Quebec MDs opting out of medicare. Montreal Gazette.

19. Commonwealth fund (2013) Wait times for specialist appointment.

20. Currie G, Donaldson C, Lu M (2003) What Does Canada Profit from the
For-Profit Debate on Health Care? Canadian Public Policy / Analyse De Politiques 29(2): 227-251.

21. Canadian Institute of Health Information (2018) Benchmarks for treatment and wait time trending across Canada.

22. Canadian Institute of Health Information (2018) Retrieved from National Health Expenditure Trends 1975 to 2018.

\section{Your next submission with Juniper Publishers will reach you the below assets}

- Quality Editorial service

- Swift Peer Review

- Reprints availability

- E-prints Service

- Manuscript Podcast for convenient understanding

- Global attainment for your research

- Manuscript accessibility in different formats

( Pdf, E-pub, Full Text, Audio)

- Unceasing customer service

Track the below URL for one-step submission https://juniperpublishers.com/online-submission.php 